\title{
After some 350 years - zero declination again in Paris
}

\author{
Mioara Mandea ${ }^{1}$ and Jean-Louis Le Mouël ${ }^{2}$ \\ ${ }^{1}$ CNES - Centre National d'Etudes Spatiales, 2 Place Maurice Quentin, 75039 Paris CEDEX 01, France \\ ${ }^{2}$ Institut de Physique du Globe de Paris, Sorbonne Paris Cité, Univ. Paris Diderot, UMR7154 - CNRS, \\ 1 rue Jussieu, 75238 Paris CEDEX 05, France
}

Correspondence to: Mioara Mandea (mioara.mandea@cnes.fr)

Received: 4 May 2016 - Revised: 1 August 2016 - Accepted: 15 August 2016 - Published: 14 September 2016

\begin{abstract}
The main part of the geomagnetic field - produced by a dynamo process in the Earth's outer core changes its direction and strength in time, over timescales from months to centuries, even millennia. Its temporal variations, known as secular variation and secular acceleration, are crucial ingredients for understanding the physics of the deep Earth. Very long series of measurements therefore play an important role. Here, we provide an updated series of geomagnetic declination in Paris, shortly after a very special occasion: its value has reached zero after some 350 years of westerly values. Indeed, during October and November 2013, the declination at the Chambon la Forêt geomagnetic observatory changed from westerly to easterly values, the agonic line then passing through this place. We take this occasion to emphasize the importance of long series of continuous measurements.
\end{abstract}

\section{Introduction}

The observed Earth's magnetic field is the sum of several internal and external contributions. The core field is more than 1 order of magnitude stronger than the other contributions. This main part of the geomagnetic field is believed to be generated by convective motions in the Earth's iron-rich, electrically conducting fluid outer core, by a process known as the geodynamo. This geodynamo-generated field is named the core field or main field, and its temporal variation, over timescales from months to centuries, is named secular variation. The core field morphology at the Earth's surface is relatively simple, being dominated by a centered dipole-like field which accounts for some $90 \%$ of the total field. The lithospheric magnetic field, with its origin in the remanent and induced magnetization of the crust and upper mantle, is not only weaker and much less variable in time, but also of a much smaller spatial scale when compared to the large-scale core field. Its complexity comes from its geological and tectonic origins. The Earth's magnetic external fields stem from the interaction of the solar wind with the magnetosphere, and have as direct sources electric currents in the ionosphere and magnetosphere. In addition, an external current system independent of the solar wind-magnetosphere interaction exists, the so-called quiet-time daily variation $\left(S_{q}\right)$ current. It has its sources in the E-layer of the ionosphere and is driven by the interaction between neutral winds and the local plasma. To characterize these sources, measurements of the full vector magnetic field are needed.

Observing the Earth's magnetic field, since the time of the first compasses, can be regarded as the oldest branch of modern geoscience and core physics. Nowadays, measuring the magnetic field is more focussed on answering fundamental questions about the planetary deep interior and its near-space environment than on practical navigation matters. Since 1832 the Earth's magnetic field direction and strength have been continuously measured at various locations around the world, and these data represent the most important body of measurements to analyse the time evolution of the field morphology. The geomagnetic observatory network is still a crucial source of data in producing secular variation models in the past, and now, together with satellite data, enables us to better describe the internal and external field contributions.

In this paper, we first describe some key steps in measuring the geomagnetic field, in France, and then we underline the role of French magnetic observations in our knowledge of the magnetic field. 


\section{Earth's magnetic field: elements and beginnings of observation}

Measurements of the Earth's magnetic field have been taken over more than a century and a half on the ground (geomagnetic observatories and magnetic surveys) and over some decades from space (low Earth orbit magnetic satellites).

The geomagnetic field, at any particular location and time, is defined in terms of the three components $(X, Y$, and $Z$ ) that together yield $\boldsymbol{B}$, the full geomagnetic field vector. The $X, Y$ and $Z$ elements are respectively the northward, eastward and downward components of the magnetic field. The projection of $\boldsymbol{B}$ in the horizontal plane is noted as $\boldsymbol{H}$ and its direction is the magnetic north. The horizontal angle between geographic north $(X)$ and magnetic north $(\boldsymbol{H})$ is denoted $D$, the magnetic declination. A compass needle aligns itself with $\boldsymbol{H}$; navigators therefore have to apply a correction to their compass direction to regain the geographic direction. Magnetic declination onboard ships has often been referred to as magnetic variation; the needle is said to be west or east, by a certain number of degrees, from the geographic north. Last, the angle between $\boldsymbol{H}$ and $\boldsymbol{B}$ is called the magnetic inclination or dip, and is denoted $I$ (counted positive downwards).

The declination was the very first measured geomagnetic field element, due to the early use of compasses. This instrument has been known in Europe since the 12th century (e.g. Merrill et al., 1996; Poirier and Le Mouël, 2013), but it is not clear when the deviation of the needle from geographic north, i.e. the declination, became known there. Probably it was discovered independently in China.

At times when navigation became more important, the geographic north direction was linked to measurements of latitude. Generally, the astrolabe was used for determining latitude by measuring the angle between the horizon and Polaris (pole star). The position of Polaris might be located within less than $1^{\circ}$ from the north celestial pole. Apparently, Roger Bacon was the first European to question the universality of the north-south directivity of the compass in 1266 (Merrill et al., 1996). In the same epoch, Petrus Peregrinus (Pierre Pelerin de Maricourt) conducted experiments on magnetism and wrote the first treatise containing a detailed discussion of a freely pivoting compass needle, a fundamental component of a dry compass. In his letter of 1269 , Peregrinus explains how to identify the poles of a magnetized sphere (terrella) and developed physical considerations about magnetism which would not be surpassed for some 300 years.

The discovery of declination in the European area has often been ascribed to Christopher Columbus in 1492, but there is evidence from ancient sundials and compasses that declination had been known in Europe since at least the early 15 th century. The oldest declination value given by a magnetic compass known to us is dated 1451. This instrument was made by Peuerbach in Vienna. However, it is not clear whether Peuerbach understood the deviation from the geographic north as purely a property of the magnetic field or as one of the instrument. Three more compasses made by him at the same location between 1451 and 1456 indicate different declination values, although the discovery of change in declination with time (i.e. secular variation) is generally assumed to have taken place only in the early 17 th century. It was probably first noticed by Edmund Gunter in 1622 and was fully described by Henry Gellibrand in 1634 (Chapman and Bartels, 1962). Inclination was discovered in 1544 by Georg Hartmann at Nuremberg, but was probably first measured correctly by Robert Norman in 1576 (Chapman and Bartels, 1962).

There was considerable interest in explaining the direction of the magnetic field from the very beginning of the 17th century and onwards. William Gilbert published his book De Magnete in 1600; he was the first to state that the Earth behaves like a giant spherical magnet. He tried to explain why a permanently magnetized compass needle points towards the north. At the same time, Guillaume Le Nautonier, a French cartographer, published in 1602-1604 Mecometrie de l'eymant c'est a dire la maniere de mesurer les longitudes par moyen de l'eyment (Mandea and Mayaud, 2004). In his book, Le Nautonier shows a global map on which the magnetic Equator and the magnetic poles (different from the geographic ones) are indicated.

From the 17th century, declination and inclination measurements started to be made on a more regular basis, giving the direction of the local geomagnetic vector, more or less continuously, in different places around the globe. Relative measurements of the intensity (or the magnitude) of this vector were made from the 1790 s, by comparing the "swing time" of a needle at the current location with that measured at a reference site. It is only in 1825 and 1830 that Denis Poisson and Carl Friedrich Gauss developed along somewhat different lines the theory of an absolute measurement of the magnetic field intensity, or strength. Simultaneously, Gauss built a magnetometer capable of providing reliable measurements of intensity. Gauss also established the first magnetic observatory in Göttingen in 1832. Moreover, Gauss and Wilhelm Weber founded the Magnetischer Verein (Magnetic Union) which, from 1834 to 1841, supported the growth of a geomagnetic network through Europe; in this context, magnetometers were installed at sites such as Berlin (1836), Dublin (1838), Greenwich (1838), Prague (1839), and Munich (1841).

In France, following a long activity in the field of Earth's magnetism, the national magnetic observatory started its activity in 1883. Before that date, declination and inclination measurements had been taken since 1541 and 1676 respectively. In the following, we focus on the Paris declination series only.

\subsection{The Paris declination series}

Early declination data can be found in published catalogues or time series. 


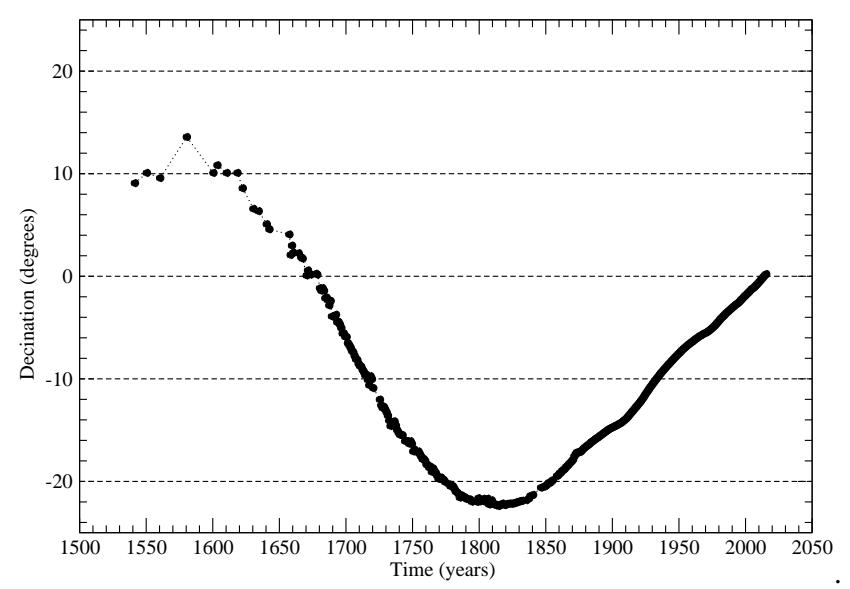

Figure 1. Paris declination series: annual means of declination corrected and adjusted to Chambon la Forêt observatory (see Alexandrescu et al., 1996, for details)

For French catalogues, we can quote the Guillaume de Nautonier one (Mandea and Mayaud, 2004) and the one published by Guillaume Delisle around 1705 (with more than 10000 measurements, which can be found in the Archives Nationales de Paris). Large efforts have been made to improve the existing database of historical observations, including the navigation measurements (Jackson et al., 2000; Jonkers et al., 2003).

Another category of sources is made of time series at a given location; for a mere handful of sites, series with more or less regular observations, spanning a few centuries, do exist. We can quote the time series of declination and sometimes inclination which have been compiled by (Malin and Bullard, 1981), Cafarella et al. (1992), Barraclough (1995), Alexandrescu et al. (1996) and Korte et al. (2009) for London, Rome, Edinburgh, Paris and Munich respectively.

The Paris declination series starts as early as in the 16th century, with the first measurement performed by Künstler Bellarmatus in 1541 , giving a value of $7^{\circ} \mathrm{E}$. From that epoch until the official date of the establishment of the Académie des Sciences in 1635 by Cardinal Richelieu, some 20 declination measurements were taken in the Paris area. In 1667, the Académie des Sciences decided to build an astronomical observatory in Paris and to start a programme of declination measurements. Before the beginning of the construction of the building, a first measurement was made on 21 June 1667, using a 5-inch needle. Subsequent measurements were performed from 1667 onwards, sometimes continued as a family tradition (La Hire, Cassini, Maraldi - fathers and sons). There are fewer measurements of inclination than of declination at the Paris Observatory, owing to its late discovery, but also because it was of less interest to navigators and was more difficult to measure accurately. More details about the observations of declination and inclination in the Paris region are given in Alexandrescu et al. (1996).
Two epochs are important from a historical point of view, separated by some 350 years, when declination reaches a null value. The first one is around 1663 (considering the mean of measurements in Paris and that in Issy-les-Moulineaux, i.e. measurements which are not reduced to the present-day location of the Chambon la Forêt observatory). From 1658 to 1667 we note eight values of declination around zero, in 1658, 1660 (two measurements), 1663, 1664, 1666, and 1667 (two measurements) - see also Table 4 in Alexandrescu et al. (1996). Among them three values of full $0^{\circ}$ declination were observed at Paris, in 1658, 1660 and 1666, the last two by Abbé Picard with a Picard needle of 5 inches. In 1663 one more $0^{\circ}$ measurement was made by Thévenot at Issy-les-Moulineaux, some $3 \mathrm{~km}$ from the Paris observatory. The ones for which the month and day are known are on 21 June $1663\left(0^{\circ} 0^{\prime}\right)$ and 21 June $1667\left(-0^{\circ} 15^{\prime}\right)$, both at summer solstice in the Northern Hemisphere. Let us underline that all declination measurements made in the Paris area (Issy-les-Moulineaux, Montsouris et Montmorency) and in previous French magnetic observatories (Saint-Maur and Val-Joyeux) are reduced to the current location of Chambon la Forêt. In Alexandrescu et al. (1996) a detailed discussion of the applied corrections is given. The annual means of declination (1541-2015), adjusted to the Chambon la Forêt observatory, are presented in Fig. 1.

The second period with a nearly null value of declination is October-November 2013. Figure 2 shows the daily variation of declination over the last 4 months of 2013, indicating a change in the declination sign over October-November 2013.

To give a flavour of the early interest in variation of declination in Paris, and a possible approach to its estimation and null values, we mention the note left by a French astronomer who tried to represent the declination in Paris by a polynomial. In Good et al. (1819) we can read that

M. Burckardt, an ingenious French astronomer, invented a formula to represent the magnetic declination observed at Paris; thus if $t$ denotes the number of years from 1663, the tangent of the declination is

$$
\begin{aligned}
0.449 \sin \left(25^{\prime} 7^{\prime \prime}\right) t & +0.0425\left[\sin \left(50^{\prime} 13^{\prime \prime}\right) t\right]^{2} \\
& +0.0267\left[\sin \left(1^{\circ} 40^{\prime} 26^{\prime \prime}\right) t\right]^{4}
\end{aligned}
$$

It follows from this formula that the eastern declination diminished from 1448, when it was maximum of $24^{\circ} 10^{\prime}$, to 1660 or 1663 , when it was nothing at Paris. Reckoning an equal period backward from 1448 gave 1233 for the earlier epoch when there was no declination. A little before this the invention of the mariner's compass is generally dated. According to Burckardt's theorem, the maximum of the western declination at Paris will be in the year 1831; thought it will not vary more than $20 \mathrm{~min}$ from that time to 1878 . We mention these 


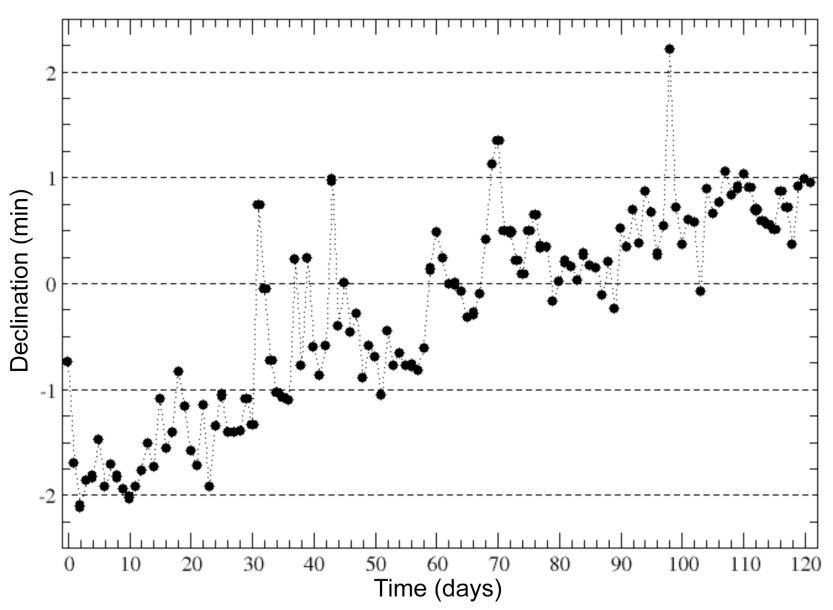

Figure 2. Chambon la Forêt declination: daily means from 1 September 2013 to 31 December 2013.

as curious results of this astronomer's formula; but would by no means understood as affirming their accuracy.

Burckardt's estimates are quite interesting, considering the time when he developed this approach. The values indicated are indeed in good agreement with measurements in Paris at the given epochs: indeed $0^{\circ}$ declination in 1660 and 1663 . The maximum western declination was measured in 1796 ( $23^{\circ} 45^{\prime}$ by Bouvard); over the period (1794-1831) the declination was around $22^{\circ}$.

\subsection{Declination series and the deep Earth's interior}

To analyse the temporal variations of the core magnetic field, it is of course essential to have available long series of data. To the slowly varying secular variation, we note additional characteristics. One specific feature of the declination variation we are interested in are the so-called "geomagnetic jerks", defined as abrupt changes in the secular variation and completed in a short time (see more details in Mandea et al., 2010; Brown et al., 2013). The temporal resolution of annual means is not adequate to get very accurate information on the characteristics of these events; however, long declination series such as the Paris one are the only sets of data which can be used to detect these events prior to the 20th century.

To enhance rapid events, the first time derivative is computed after applying an 11-year smoothing. The Paris declination curve clearly exhibits a number of changes in the secular variation, as shown in Fig. 3. These changes are more rounded as a result of the use of the filter; nevertheless, the geomagnetic jerks can still be clearly identified. The figure clearly shows that, prior to the 20th century, one of the most prominent geomagnetic jerks appears around 1870 . This event is also observed in four other European locations (Alexandrescu et al., 1997) and has been recently detected in the Munich curve (Korte et al., 2009), although a few

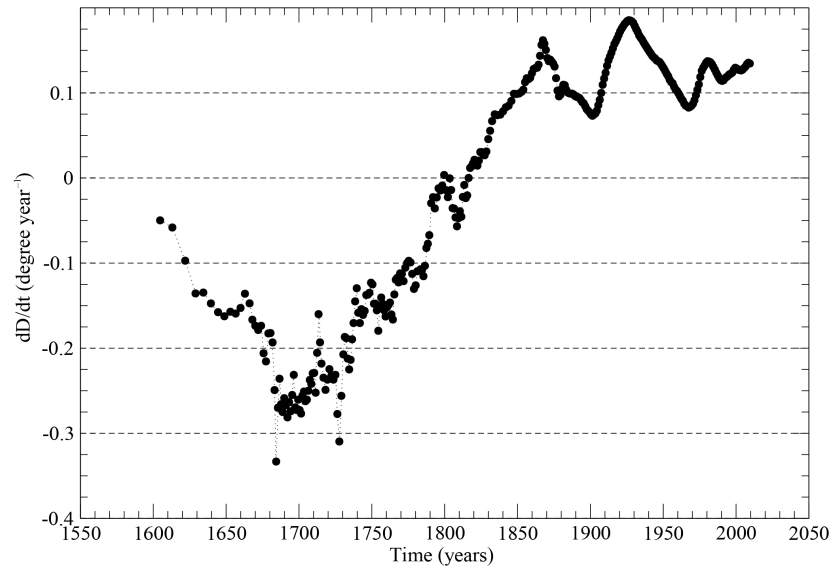

Figure 3. Paris declination series: secular variation of the declination computed with an 11-year smoothing filter.

years earlier. Going farther back in time, there is evidence of changes in the secular variation trend, supported by measurements around the epochs: $1600,1665,1700,1730,1750$, $1760,1770,1810,1870,1890$, and 1900. These dates are close to those detected by Qamili et al. (2012): 1603, 1663, $1703,1733,1751,1763,1770,1810,1868-1870,1888$, and 1900 , when analysing the temporal behaviour of the difference between predicted and actual geomagnetic field model values for successive intervals from 1600 to 1980 , based on the Gufm1 geomagnetic model (Jackson et al., 2000). Let us note that here we use the term "geomagnetic jerk" for all these events; however, as noted by Mandea and Olsen (2009), we must make a distinction between geomagnetic jerks and rapid secular variation fluctuations.

Considering the origin of geomagnetic jerks in the fluid outer core, their signature on the measured magnetic field at the Earth's surface may differ from place to place, which explains why there is no perfect temporal coincidence between the different declination series.

\section{Conclusions}

In this paper we updated the Paris series with the last 20 years of data, considering the event of zero declination through the Chambon la Firêt observatory. This is not a unique incident in Europe and an image of the declination observations at other observatories and repeat stations to demonstrate the westerly drift of the agonic line is provided by the declination map of Europe for the epoch 2006, a product of the MagNetE group (Duma et al., 2012). This map also includes the secular variation estimates for Europe.

The evolution of the Earth's magnetic field is intimately linked to the history of the Earth, allowing insights into the inner workings of our planet. Furthermore, the magnetic field is an important component in shielding the Earth's surface from solar emissions. Hence, understanding its behaviour 
is crucial, even if long-term accurate predictions are not presently possible. It is inevitable that the geomagnetic field will continue to exhibit secular variation at all timescales, and its strength continues to change, producing changes in the structure and dynamics of the magnetosphere. One can expect a corresponding change in the geometry of the magnetosphere, which is controlled to first order by a balance between static pressure generated by the geomagnetic field and the dynamic pressure of the solar wind. The possible consequences for our planet are not yet completely acknowledged.

Understanding how the future geomagnetic field varies is strongly dependent on how well we know the past magnetic field. And for this, geomagnetic data, represented by the declination curve, remain a unique dataset.

\section{Data availability}

Data are available as following:

a. The annual means

- 1541-1994: from Alexandrescu et al. (1996);

- 1995-2014: from http://www.geomag.bgs.ac.uk/data_ service/data/annual_means.shtml.

The Paris declination series, reduced to the current location of Chambon la Forêt observatory, is available on request.

b. The daily means

- from http://www.bcmt.fr/clf.html.

Author contributions. Mioara Mandea and Jean-Louis Le Mouël contributed equally to this work, which is a legacy of the time they spent in Chambon la Forêt observatory.

Acknowledgements. This "null-declination" event is dedicated to so many observers, who, with constant patience, measured the geomagnetic field over centuries. Special thanks are given to the operators of Chambon la Forêt observatory. We gratefully acknowledge constructive suggestions from two anonymous reviewers.

Edited by: M. G. Johnsen

Reviewed by: two anonymous referees

\section{References}

Alexandrescu, M., Courtillot, V., and Le Mouël, J.-L.: Geomagnetic field direction in Paris since the mid-sixteenth century, Phys. Earth. Planet. Inter., 98, 321-360, doi:10.1016/S00319201(96)03194-9, 1996.

Alexandrescu, M., Courtillot, V., and Le Mouël, J.-L.: High resolution secular variation of the geomagnetic field in western Europe over the last 4 centuries: Comparison and integration of historical data from Paris and London, J. Geophys. Res., 102, 2024520258, 1997.
Barraclough, D.: Observations of th Earth's magnetic field in Edinburgh, from 1670 to the present day, T. Roy. Soc. Edinburgh Earth Sci., 85, 239-252, 1995.

British Geological Survey: Worldwide Observatory Annual Means, http://www.geomag.bgs.ac.uk/data_service/data/annual_ means.shtml, last access: September 2016.

Brown, W., Mound, J., and Livermore, P.: Jerks abound: An analysis of geomagnetic observatory data from 1957 to 2008, Phys. Earth. Planet. Inter., 223, 62-76, 2013.

Cafarella, L., DeSantis, A., and Meloni, A.: Secular variation in Italy from historical geomagnetic field measurements, Phys. Earth. Planet. Inter., 73, 206-221, 1992.

Chapman, S. and Bartels, J.: Geomagnetism, Oxford University Press, London, 1962.

Duma, G., Leichter, B., and the MagNetE Group: Magnetic Declination Chart 2006 of Europe, Ann. Geophys., 55, 1053-1059, doi:10.4401/ag-5575, 2012.

Good, J. M., Gregory, O., and Bosworth, N.: Pantologia. A new (cabinet) cyclopedia, London, available at: https://archive. org/details/pantologiaanewc01greggoog (last access: September 2016), 1819.

Jackson, A., Jonkers, A. R. T., and Walker, M. R.: Four centuries of geomagnetic secular variation from historical records, Philos. T. Roy. Soc. Lond. A, 358, 957-990, 2000.

Jonkers, A. R. T., Jackson, A., and Murray, A.: Four centuries of geomagnetic data from historical records, Rev. Geophys., 41, 1006, doi:10.1029/2002RG000115, 2003.

Korte, M., Mandea, M., and Matzka, J.: A historical declination curve for Munich from different data sources, Phys. Earth. Planet. Inter., 177, 161-172, 2009.

Malin, S. and Bullard, E.: The direction of the Earth's magnetic field at London, 1570-1975, Philos. T. Roy. Soc. Lond., 299, 357423, 1981.

Mandea, M. and Mayaud, P.: Guillaume Le Nautonnier - un précurseur du magnétisme terrestre, Revue d'Histoire des Sciences et de leur applications, 57, 161-174, 2004.

Mandea, M. and Olsen, N.: Geomagnetic and archeomagnetic jerks: Where do we stand?, EOS, Trans., 90, 208, 2009.

Mandea, M., Holme, R., Pais, A., Pinheiro, K., Jackson, A., and Verbanac, G.: Geomagnetic Jerks: Rapid Core Field Variations and Core Dynamics, Space Sci. Rev., 155, 147-175, 2010.

Merrill, R., McElhinny, M., and McFadden, P.: The Magnetic Field of the Earth, Academic Press, San Diego, 1996.

Poirier, J.-P. and Le Mouël, J.-L.: Une brève histoire du magnétisme - De l'aimant à la Terre, Belin, Paris, 224 pp., 2013.

Qamili, E., De Santis, A., Isac, A., Mandea, M., Duka, B., and Simonyan, A.: Geomagnetic jerks as chaotic fluctuations of the Earth's magnetic field, Geochem. Geophy. Geosy., 14, 839-850, 2012. 